Macedonian Pharmaceutical Bulletin, 66 (Suppl 1) 23 - 24 (2020)

Online ISSN $1857-8969$

UDC: $637.131 .8 .046(497.7)$

DOI: 10.33320/maced.pharm.bull.2020.66.03.011

Short communication

\title{
Mineral enrichment of milk - nutritional benefits and future perspectives
}

\author{
Liljana Anastasova ${ }^{1}$, Tanja Petreska Ivanovska ${ }^{2}$, Zoran Zhivikj $^{2}$, Rumenka Petkovska ${ }^{1}$, \\ Lidija Petrushevska-Tozi ${ }^{2}$ \\ ${ }^{1}$ Institute of Applied Chemistry and Pharmaceutical Analysis, Faculty of Pharmacy, \\ Ss. Cyril and Methodius University, Mother Theresa 47, 1000 Skopje, Republic of North Macedonia \\ ${ }^{2}$ Institute of Applied Biochemistry, Faculty of Pharmacy, Ss. Cyril and Methodius University, \\ Mother Theresa 47, 1000 Skopje, Republic of North Macedonia
}

\section{Introduction}

Micronutrient deficiency affects millions of people in the world in both developing and developed countries, causing considerable negative impact on individual well-being, social welfare and economic productivity (Nikooyeh \& Neyestani, 2017). The proposed strategies to overcome this problem include change in the dietary lifestyle, dietary supplementation and enrichment of food (Ocak and Rajendram, 2013). Among food products that can be used as vehicles for mineral enrichment, milk and dairy products have been intensively studied. Their unique composition with the mixture of fat and aqueous phase makes it an ideal vehicle for different types of fortificants/nutrients (Nikooyeh \& Neyestani, 2017). This review will provide overview of the advantages of using milk as a delivery vehicle for mineral enrichment, the most commonly added minerals for improving nutritional quality of milk and some technological aspects of the process of milk enrichment.

\section{Milk-based micronutrient supplementation}

Milk and dairy products are important source of dietary minerals, particularly calcium and magnesium, but they also contain trace amounts of iodine, selenium, iron and zinc.
Milk is the best natural source of calcium. Calcium exists in a colloidal form as caseinatephosphate complex, readily released during digestion in vivo, hence its potential bioavailability is high. Therefore, milk has been commonly used as a vehicle for additional calcium delivery (Singh et al., 2007). Magnesium in milk and dairy products is a major contributor to dietary intake of magnesium. Milk and dairy products are, in fact, one of the main dietary sources of magnesium particularly for children, contributing approximately $10-30 \%$ of the total magnesium intake (EFSA, 2015). With better understanding of magnesium in the dairy system, there is potential for milk and dairy products to be developed to deliver increased levels of bioavailable magnesium, as well as calcium (Oh \& Deeth, 2017). Milk and dairy products represent poor sources of selenium, and some studies have investigated the fortification of milk with selenium. Alzate et al. (2010) reported that fermentation of Se-enriched milk is an interesting strategy to improve human intake of several organic compound of selenium. Zinc is one of the essential minerals found in milk. Studies dealing with enrichment of milk with zinc are scarce in literature. A study of $\mathrm{Zn}$ enrichment at the levels of milk consumed by adolescent girls affected positively the intake and absorption of $\mathrm{Zn}$. Therefore, to meet the physiological requirements and to ensure adequate $\mathrm{Zn}$ status, the consumption of

*lbogdanovska@ff.ukim.edu.mk 
enriched milk for more than 27 days can be recommended (Mendez et al., 2012). Iron deficiency comes from diverse origins but is mainly related to the low availability of iron in food products. Iron fortification of foodstuffs remains the cheapest way to avoid iron deficiency and insure the daily intake over a long period. An advantage of using milk and dairy products as a vehicle for iron fortification/enrichment is the relatively high bioavailability (Gupta et al., 2015). Iodine is naturally present in small levels in milk. However, milk is one of the largest sources of dietary iodine. There are several studies that emphasize the beneficial effect of consuming iodine-fortified milk. It seems that iodine fortified milk, in addition to iodized salt, can be considered a good dietary source to ensure iodine sufficiency especially during the lactation period (Bouga et al., 2018).

The enrichment of milk, a process where minerals in the form of salts are added to milk, is dependent on several factors such as the nutritional requirements of the intended target population, the effect of the added micronutrients on the functional or sensory characteristics of milk and the stability of the added micronutrients during processing and storage of milk (Ocak and Rajendram, 2013). The most common problem related to this process is the development of unacceptable changes in the sensorial properties such as off-flavors, bad taste as well as loss in vitamin $\mathrm{C}$ which is the case when iron salts are added to milk. The development of novel, advanced techniques such as micro/nanotechnology will bring revolutionary changes in the process of milk enrichment. Encapsulated ingredients have a superior performance, such as successful delivery of ingredients into foods, and a potential for enhancing bioavailability of bioactive components. Up to date, microencapsulation has been used to deliver food ingredients and bioactive compounds and can be used as a suitable mode of delivery of minerals in dairy products (Kwak et al., 2014).

\section{Conclusion}

Current micronutrient interventions in the field of public health aim at adding the lacking minerals to people's diets (either by directly fortifying food or in the form of supplements). The development in modern technologies in future will improve the process of mineral enrichment resulting in "modern mineral enriched milk" in order to address consumer's nutritional requirements.

\section{References}

Alzate, A., Perez-Conde, M.C., Gutierrez, A.M., Camara, C., 2010. Selenium-enriched fermented milk: A suitable dairy product to improve selenium intake in humans. Int. Dairy J. 20, 761-769.

Bouga, M., Lean, M.E.J., Combet, E., 2018. Contemporary challenges to iodine status and nutrition: the role of foods, dietary recommendations, fortification and supplementation. Proc. Nutr. Soc. 112.

EFSA panel on dietetic products, nutrition and allergies, 2015. Scientific opinion on dietary reference values for magnesium. EFSA J. 13, 1-63.

Gupta, C., Chawla, P., Arora, S., 2015. Development and evaluation of iron microencapsules for milk fortification. Cyta - J. Food 13, 116-123.

Kwak, H., Mijan, M., Ganesan, P., 2014. Application of Nanomaterials, Nano- and Microencapsulation to Milk and Dairy Products, in: Kwak, H. (Ed.), Nanoand Microencapsulation for Foods. John Willey \& Sons, Ltd, New York, NY.

Mendez, R.O., Galdamez, K., Grijalva, M.I., Quihui, L., Garsia, H.S., de la Barca, A.M.C., 2012. Effect of micro-nutrient-fortified milk on zinc intake and plasma concentration in adolescent girls. J. Am. Coll. Nutr. 31, 408-414.

Nikooyeh, B., Neyestani, T.R., 2017. Using fortified milk as a vehicle for nutrients: From infancy to senescence, in: Watson, R., Collier, R., Preedy, V. (Eds.), Dairy in Human health and disease across the lifespan. Academic press, Cambridge, Massachusetts, pp. 145-154.

Ocak, E., Rajendram, R., 2013. Fortification of milk with mineral elements, in: Preedy V., Srirajaskanthan R., Patel V. (Eds.), Handbook of Food Fortification and Health. Nutrition and Health. Humana Press, New York, NY, pp. 213-224.

Oh, E., Deeth, H.C., 2017. Magnesium in milk. Int. Dairy J. 71, 89-97.

Singh, G., Arora, S., Sharma, G.S., Sindhu, J.S., Kansal, V.K., Sangwan, R.B., 2007. Heat stability and calcium bioavailability of calcium-fortified milk. LWT Food Sci. Technol. 40, 625-631. 